\title{
Bases epistemológicas para uma abordagem contemporânea ao ensino de projeto. Os meios digitais, o professional reflexivo e a ruptura dos velhos paradigmas
} \author{
paradigm shift \\ - Pedro Gabriel de Sousa Lima \\ Departamento de Arquitetura e Urbanismo, \\ Neliza Maria e Silva Romcy \\ Universidade Federal do Ceará, Brasil \\ sousadegabriel@gmail.com \\ Departamento de Arquitetura e Urbanismo, \\ Universidade Federal do Rio Grande do Norte, \\ Brasil \\ - Débora de Oliveira Sousa \\ neliza.romcy@gmail.com \\ Departamento de Arquitetura e Urbanismo, \\ Universidade Federal do Ceará, Brasil \\ debora.oliveira.sousa@hotmail.com
}

Epistemological basis to a contemporary approach for design teaching. The digital media, the reflective professional and the

\begin{abstract}
We now live on the digital era. Technological innovations don't stop to come to light, and our society little by little become more permeable and sensible to the present-day. The architect who refuses to just repeat architecture styles enters in a avant-garde position and gives intellectual impulses towards finding through your work a original proposal that will answer in fact the demands of a society that is correlate with your present-time. How to teach him to deal with the novel situations of the digital era and the paradigms to be used as basis and how should be the new pedagogical structure?
\end{abstract}

Keywords: Digital Media, Parametric Architecture, Design Teaching, Digital Fabrication, Reflection-in-action

\section{Introdução}

Vivemos na era digital. Inovações tecnológicas não param de surgir, e nossa sociedade aos poucos se torna mais permeável e sensível aos novos tempos. $\mathrm{O}$ arquiteto que se nega a apenas repetir estilos de arquitetura entra numa posição de vanguarda e dá impulsos intelectuais em prol de encontrar através de seu trabalho uma proposta original que responderá de fato as demandas de uma sociedade que esteja correlata ao seu tempo (Gropius, 1972).

Nesse contexto, os novos meios digitais incidem de forma cada vez mais efetiva sobre nossas vidas. $\mathrm{Na}$ prática projetual, e, consequentemente, da criação ao produto final, começam a provocar rachaduras nas concepções modernistas a qual usamos como modelo, principalmente no ensino de projeto. $O$ projeto digital causa impactos não apenas por conta da performance ou do conteúdo formal excepcional, mas também pela sua estrutura única de teorias projetuais e conceitos arquitetônicos. O termo "digital design thinking" implica uma mudança drástica no sentido da forma, na natureza do conhecimento projetual e da criação. $\bigcirc$ arquiteto contemporâneo se posiciona como um articulador de informações e processos e esse modo de pensar requer novas bases epistemológicas, ruptura dos paradigmas de projeto, enovos métodos de ensino (Oxman, 2006).
$\mathrm{Na}$ busca de uma compreensão dessas mudanças na arquitetura, urbanismo e design, estabeleceram-se algumas definições. A parametrização "corresponde a um sistema constituído por elementos que se relacionam e sofrem um auto ajuste quando uma variável é modificada. Esse sistema pode ser representado através de um modelo conceitual composto por variáveis e operadores matemáticos lógicos que irão definir uma determinada função" (Woodburry, 2010). É fundamental o entendimento de prototipagem e fabricação digital que, grosso modo, "[...] referem-se a métodos que permitem a transição do modelo digital para o físico de maneira automatizada. Considerando que o produto final pode ser uma maquete ou um elemento construtivo, ou ainda um protótipo" (Pupo, 2009).

O objeto concebido pelas novas tecnologias é programado por softwares e fabricado digitalmente pelo arquiteto, ele está no comando a manipular as novas ferramentas, as ferramentas digitais, aplicando seu conhecimento para resolver problemas e pensando de modo projetual. Graças a essa expansão do limite projetual ocasionado por essas ferramentas, tal objeto adquire geometrias bem mais complexas que os padrões anteriores; é representado de outra maneira, saindo para sempre da representação em papel; é concebido para ser dinâmico e ajustável, sendo ele um processo, em prol de uma melhor performance, calculando-se a incidência de luz ou de 
ventos, por exemplo; abandona os modelos modernistas de conceituação, geração e produção, pois a criação do modelo digital acontece de forma diferente da criação do modelo formalista (Oxman, 2007).

Partindo disto, o presente artigo se propõe a investigar o momento de ruptura de paradigmas também vivenciado pela Bauhaus e seus impactos no sentido de traçar paralelos com o momento atual, bem como investigar sobre a constituição de um possível método para o ensino de projeto através dos estudos deDonald A. Schön a respeito do profissional reflexivo e como instruí-lo e adaptá-lo para esse novo momento em simbiose com a inserção dos meios digitais e o uso da parametrização nas universidades brasileiras.

\section{Como a Inserção de Meios Digitais Mudou os Velhos Paradigmas}

Para que a inserção dos conceitos digitais seja aplicada de forma efetiva é necessária uma análise dos ganhos e das consequências de sua utilização no processo projetual. As ferramentas computacionais começaram a ser utilizadas como um auxílio ao arquiteto no processo de representação projetual, de forma a otimizar o tempo necessário para essa tarefa. $\mathrm{O}$ arquiteto mudou o meio pelo qual ele projetava mas continuava aplicando os mesmos processos utilizados na representação em papel. O ganho de tempo existiu, mas não apresentou mudanças nos métodos de projeto, de fato. Mesmo com a subsequente evolução das ferramentas de modelagem digital 3D, mudanças profundas na prática projetual só puderam ser observadas com o surgimento de novos meios de conceituação (Oxman, 2007), isto é, com uma evolução na forma de pensar projetualmente, inteiramente digital.

Nesse processo de evolução dos paradigmas, a plataforma BIM, Building Information Modeling, se mostra como um modificador da prática projetuale se refere não a um software específico, masrepresenta um conceito muito mais amplo, pois "com a tecnologia BIM é possível criar digitalmente modelos virtuais precisos de uma construção. Eles oferecem suporte ao projeto ao longo de suas fases, permitindo melhor análise e controle do que os processos manuais. Quando concluídos, esses modelos gerados por computador contêm geometria e dados precisos necessários para o apoio às atividades de construção, fabricação e aquisição por meio das quais a construção é realizada." (Eastman, Teicholz, Sacks e Liston, 2011). Se trata de uma atividade que modifica todo o processo na indústria da construção através da representação de objetos por regras ou parâmetros que definem as características formais deste como também propriedades não geométricas. Este permite o desenvolvimento mais assertivo com relação à correspondências entre desenhos e com maior controle do usuário através das regras do modelo 3D que fazem com que o objeto se atualize automaticamente.

Embora este já seja um ganho considerável à verdadeira potencialidade da plataforma BIM se encontra no aglomerado de informações inerentes ao modelo. Tais informações permitem um avanço significativo em toda a cadeia construtiva impactando desde a fase conceitual do projeto até a utilização do objeto arquitetônico. Dessa Forma, o arquiteto começa a estar diante de uma nova postura de projeto. Ele vai agora , ao invés de desenhar linhas e pontos geométricos em uma plataforma 2D, transcrever suas ideias e conhecimentos através de um meio que cruza processos de informações, ou seja, indicando paredes, janelas, vigas, coberturas, lajes, etc. $\mathrm{O}$ arquiteto agora constrói seu projeto através de uma modelagem 3D que guarda as informações referentes ao objeto criado. Com o intermédio dessa ferramenta, o arquiteto modela através de informações, de parâmetros, e processos.

Assim é possível alcançar uma maior performance e qualidade do edifício através de cálculos prévios, análises e simulações energéticas; custos de tempo e dinheiro bem menores, podendo também prever erros de execução durante a obra através de um planejamento prévio seguro, com a capacidade de mudar ou repensar o projeto de forma rápida e fácil; maior integração com outros softwares, outras disciplinas de projeto e entre os profissionais responsáveis pela obra através de uma opção de teamwork, ainda durante a fase de desenvolvimento do projeto; representação 3D integrada a uma representação $2 \mathrm{D}$ com grande precisão, havendo inclusive correção automática de pequenos erros tais como alinhamento e escala, passíveis no processo de representação em papel (Eastman, Teicholz, Sacks e Liston, 2011).

Embora o BIM seja uma tecnologia que inicia seus primeiros passos de consolidação no mercado e nas universidades brasileiras, grande parte dos seus usuários tira partido dessa plataforma de modo simplificado, desenvolvendo os projetos através de uma modelagem 3D que deixa de lado as vantagens da modelagem inteligente. Por modelagem inteligente entende-se aquela que além da função representativa se propõe a arquivar uma grande quantidade de informações e dados através de processos e utiliza parâmetros que, quando modificados, refletem diretamente nas características e propriedades do objeto sejam elas geométricas, espaciais, ambientais ou energéticas. Dessa forma, para além do desenvolvimento do BIM, surgem ferramentas como o Rhinoceros e o plugin Grasshopper, que facilitaram o reconhecimento da chamada Arquitetura Generativa, "provision of computational mechanisms of generative process [...], shapes and forms are considered to be a result of preformulated nerative process" (Oxman, p. 106, 2007).

\section{Possíveis modelos paradigmáticos}

As mídias digitais se apresentam como ferramentas generativas para a derivação da forma. $O$ método convencional onde a forma emerge unicamente através da capacidade criativa do arquiteto é substituído por um método com maior embasamento. Os parâmetros definidos pelas necessidades do projeto irão compor uma lógica capaz de gerar inúmeras possibilidades capazes de resolver tais questões. Nesse momento cabe ao arquiteto, com o uso de sua capacidade criativa e conhecimento teórico e tácito (Schön, 
2000), determinar a opção mais apropriada.

A pesquisadora Rivka Oxman já nos mostra 3 possíveis modelos paradigmáticos a serem levados em consideração que se utilizam de forma efetiva de softwares e ferramentas computacionais. Modelos de formação são aqueles onde o estudo topológico possui prioridade e o projeto se torna dinâmico, sendo caracterizado pelas técnicas de design paramétrico ou formação por animação. Modelos gerativos ou generativos que empregam o uso de gramáticas da forma, formulando sistemas e design e programação. Modelos de performance são projetos conduzidos por simulações, feitas por muitos softwares de simulação, análise e avaliação. (Oxman, 2006; 2007)

Esses novos métodos se aplica não somente ao contexto formal ou estrutural do objeto, mas a todas suas características, visando sempre a otimização e uma alta performance, trabalhando também em conjunto. A arquitetura performativa possui o desempenho do edifício como fator definidor e garante um resultado coerente à todas as análises qualitativas e quantitativas realizadas acima de qualquer conceito formal já definido.

Embora seja incontestável as novas possibilidades permitidas pelo design digital a sua não utilização por ainda uma grande parte das universidades brasileiras funciona como o indicativo da necessidade de uma nova visão sobre o mundo contemporâneo. A geração da forma pode agora ser obtida através de uma força modeladora performativa agindo sobre o conteúdo e o conteúdo formal, garantido um resultado mais eficiente baseado em parâmetros já estabelecidos e com uma maior assertividade.

Fechando o ciclo de processos do projeto digital, a fabricação digital, a prototipagem rápida e a impressão 3D tornam possível um futuro onde modelos de design, integrados ao BIM, permitem uma produção inteiramente digital, sem o uso de papel, onde a manufatura se dá por máquinas de forma quase automática e que permite ser ainda meio de criatividade importante para o projeto total. (Oxman, 2005). Segundo Tramontano e Soares, o uso dos meios digitais integrados ao processo por meio da parametrização possibilita a concepção de formas cada vez mais complexas e ainda assim possíveis de serem produzidas em série na indústria, com o uso de máquinas de controle numérico, ou máquinas $\mathrm{CNC}$, Computer Numerically Controled (Tramontanoe Soares, 2012).

O desenvolvimento tecnológico permitiu uma maior consciência do objeto por parte do profissional e uma antecipação dos possíveis problemas em sua execução. 0 levantamento de possibilidades pode ser realizado pelo sistema através da análise dos dados disponíveis, auxiliando o arquiteto em sua tomada de decisão, que agora se embasa em fatores lógicos e fundamentados que corroboram para a manifestação da forma.

\section{Ruptura de Paradigmas: o Exemplo da Bauhaus}

Refletindo sobre esse projetar digital, é possível traçar um paralelocom o rompimento de paradigmas desencadeado pela Bauhaus, uma escola de arte racionalista que se manifestou no período entre guerras (1919-1933) e culminou na cristalização das ideias modernistas. Essa escola mundialmente conhecida obteve tal posto em decorrência das inovações que propiciou a nível acadêmico, ao nível da formação do profissional e da prática, ao nível da construção e produção industrial, além da conhecida repercussão formal. A partir dela, paradigmas também evoluíram de modo a condizer de fato com a sociedade e a cultura da época, bem como a se utilizar das tecnologias próprias da época. Eram necessárias mudanças no modo de ver e instruir o futuro arquiteto: "A maneira como se ensina arte e design à juventude atual, entretanto, raramente ajuda a compreender problemas artísticos contemporâneos. Ela sai da escola ou da universidade abarrotada de conhecimentos, mas raramente lhe foi dada a tarefa de encontrar-se a si mesma" (Gropius, p. 80, 1972).

Ao final da Primeira Guerra Mundial a Alemanha se encontrava derrotada e dilacerada pelo conflito de classes. Os intelectuais reivindicam um renascimento cultural capaz de auxiliar na superação da tragédia e contradizer o irracionalismo político que alargava as contradições sociais. Era necessário negar também a forma como se vinha projetando, utilizando erroneamente o conceito de tipo como mera repetição de estilos. Tal forma de fazer arquitetura era superficial, sem se aprofundar nos problemas reais do mundo moderno, além de formar arquitetos deficientes que apenas repetiam o que já vinha sendo feito. Nesse contexto, e fazendo questionamentos no modo de se fazer arquitetura, surge assim o racionalismo alemão, liderado por Walter Gropius e outros artistas, arquitetos e profissionais. Buscava-se uma nova relação entre o artesão e a indústria possibilitando a produção em larga escala, símbolo da revolução industrial, predominado a geometrização e simplificação das formas, além de uma teoria de projeto que viesse a servir de base para a ascensão do modernismo.

O principal conceito disseminado era a racionalidade que devia seenquadrar nãoapenasnocampocriativo, masem todas as ações cotidianas. Já se negava, nesse período, o privilégio da inspiração ao artista sendo o objeto arquitetônico fruto da colaboração racional e não uma obra individual idealizada por um artista.Gropiusprocurava difundir não um método pronto, mas uma abordagem que permitisse trabalhar o problema de acordo com suas peculiaridades. "Quero que o jovem arquiteto (...) crie independentemente formas autênticas, a partir de condições técnicas, econômicas e sociais a ele dadas, em vez de impor uma fórmula aprendida a um ambiente que talvez exija uma solução completamente diversa" (Gropius, 1972).

A evolução tecnológica e o uso de novos materiais como metal cromado, aço, vidro e suas utilizações na produção em larga escala impulsionaram uma renovação estética e, por consequência, uma nova metodologia projetual. No âmbito acadêmico a nova escola instaurou o principio da colaboração, assim sendo, alunos e professores desenvolviam pesquisas de forma conjunta, desmitificando o conceito do aluno que recebe 
a informação do professor de forma passiva. Acreditando que o ensino teórico era superestimado, e o ensino prático deixado de lado de forma a extinguir a criatividade do aluno, outro conceito levado como prioridade era a de que era necessário que o arquiteto desde o começo tivesse contato com aulas práticas sobre o que era estudado, através, no caso, de oficinas com artesãos competentes. A vivência do arquiteto durante o curso ser levada em consideração "partindo de uma larga concepção social da vida, [que] incumbe-lhe procurar com a ajuda de sua capacidade de organização atingir o pensamento e a sensibilidade de sua época, harmonizando a causa e a forma arquitetonicamente. Se esperamos que o arquiteto do futuro seja tão multilateral, como deverá ser então sua formação?" (Gropius, p.84, 1972).

\section{A Necessidade de Mudança, o Profissional Reflexivo e os Meios Digitais}

Com a cristalização dos paradigmas elaborados pela Bauhaus, logo a sociedade veio a limitar a escola a um mero estilo, transformando a arquitetura moderna no pastiche tão difundido que ainda hoje vivemos e observamos em nossas cidades, paradoxalmente negando a ideia de Gropius de que a "essência da vida é a contínua metamorfose"(Gropius, p. 73, 1972). Encarando as experiências de tal processo histórico podemos complementar a necessidade de mudanças no ensino e pensamento projetual para adaptá-lo a nossas novas demandas. Através da inserção efetiva dos meios digitais podemos "dar forma a nossa própria cultura, pois cultura significa a aplicação de métodos artísticos próprios, que exprimem da melhor maneira as ideias e a linha intelectual de nossa época." (Gropius, p. 118, 1972).

Donald A. Schön chegou a conceituação de um profissional que acessa informações durante a ação, seja ela qual for, buscando definir a resolução de problemas, o chamado profissional reflexivo. Ele não somente acessa a informação teórica que estuda em sala de aula ou na prática profissional em si, mas encontra respostas e produz novos questionamentos através de um método determinado, seja por experimentação, seja por improviso, em que processando dados de forma consciente e subconsciente, encontra soluções para as problemáticas que enfrenta de forma reflexiva. Através de um sistema de seeing-move-seeing ${ }^{1}$, o projetista olha de diversas formas, seja apenas olhando, seja por gestalt, para uma situação problema e descobre novos materiais de trabalho sobre o problema, fazendo um movimento de experimentação, por exemplo, em cima desse material, no sentido de transformá-lo para estabelecer um novo olhar e gerar avaliações de juízo a respeito, afirmando ou negando o movimento que foi feito. Dessa forma, ele guarda, a cada nova prática projetual, essas informações a respeito dessas resoluções para que possa acessar em outros momentos, em outros projetos (Schön, 1992). Para Schön essa é a forma como o profissional reflexivo pensa e age, através de uma conversa reflexiva com os materiais do problema.
Abordando a nova linguagem e gramática arquitetônica possível, é um profissional que sabe mais do que consegue falar e que precisará dedicar-se aos novos estudos inerentes aos uso dos novos meio digitais, para produzir este novo tipo de arquitetura. $O$ produto do arquiteto hoje é, através dos estudos de gramática da forma, programação digital e performance voltada para a sustentabilidade, um projeto do projeto, isto é, o arquiteto gerencia e articula um projeto dinâmico de programação do projeto a ser construído. Com essas mudanças, modelos muito mais complexos são possíveis através do gerenciamento das informações do projeto, bem como pode-se agora atingir altos níveis de performance e de economia.

$\mathrm{O}$ arquiteto pode lidar durante o processo de projeto com vários domínios ao mesmo tempo, se ele for um profissional já experiente, como pensar ao mesmo tempo em questões de economia de materiais enquanto projeta as lajes de um edifício e imagina a modulação dos pilares. Hoje em dia, porém, o computador pode processar esse inúmeros domínios ao mesmo tempo e então essas variáveis e inputs serão postos nesse grande algoritmo que vem a ser o projeto final e para isso é necessário que o arquiteto tenha noção e sensibilidade no que concerne a todas as questões possíveis de serem solucionadas no edifício, que passa a ser uma interface.

\section{Métodos de ensino anteriores e porque mudar}

A metodologia vigente nas escolas é fundada na racionalidade técnica, uma teoria da prática com raízes nas universidades modernas que se dedica à pesquisa e deriva da filosofia positivista de culto a ciência e ao progresso. "A racionalidade técnica diz que os profissionais são aqueles que solucionam problemas instrumentais, selecionando os meios técnicos mais apropriados para propósitos específicos. Profissionais rigorosos solucionam problemas instrumentais claros, através da aplicação da teoria e da técnica derivadas de conhecimento sistemático, de preferência científico" (Schön, p. 19, 2000). De natureza sistemática, o currículo desse profissional é baseado em um conhecimento sistemático, na maior parte dos casos, científico, que é dividido em ciência básica, ciência aplicada e espaço para ensino prático onde se espera que os estudantes aprendam a aplicar o conhecimento adquirido em sala de aula aos problemas da prática cotidiana, seu mote de pesquisa (Schön, 2000).

A ideia das escolas profissionais de que a pesquisa acadêmica renderia conhecimento profissional útil e que com essa forma de ensino se prepararia o aluno às demandas reais da prática profissional são questionáveis. A academia se distância cada vez mais da prática e da utilidade, e esse seria um ponto que nos mostra que há novas demandas que a simples pesquisa acadêmica não consegue mais dar conta. Schön comenta a respeito da pouca importância dos problemas que são resolvidos com esse tipo de ensino rigoroso hoje em dia, enquanto vários outros grandes problemas de "investigação não-rigorosa", importantes para a nossa época, estão além dos conceitos daquele conhecimento.

O profissional se forma possuindo a técnica sem possuir 
a competência necessária para lidar com ações que fujam do convencional, as zonas incertas da prática (Schön, 2000) devido ao ensino normativo até então em vigor. A realidade nos aparece com seus problemas não-delineados e caóticos com diversos fatores econômicos, políticos, e sociais que a simples aplicação de conhecimento técnico não resolve. Em casos únicos, como casos que não estão num manual técnico, o profissional que improvisa com seu repertório de conhecimentos e consegue resolver a problemática é tido como perspicaz, que possui mais talento ou intuição, não como o que possui mais conhecimentos técnicos se comparado a outros.

A racionalidade técnica tem seu valor e é importante como um fator básico de ensino, que precisa ser aprimorado ou tornado apenas parte de um todo, e não o todo. Um equilíbrio pode surgir se o improviso ou a intuição forem levados a sério. As já citadas zonas indeterminadas da prática, as situações problemáticas incertas, as situações singulares e aquelas em que há conflito de valores, já não podem mais ser contempladas pelo ensino incompleto da racionalidade técnica. Ainda há nas universidades brasileiras, a ideia de que o autor é o cara iluminado que nasceu para conceber grandes projetos, que sabe de tudo, que surge da cabeça dele a inspiração, pressupondo que isso na verdade não advenha também de uma labuta, de estudos, de exercícios e trabalho em conjunto onde todos trabalham em cima de um objetivo.

\section{Conhecimento-na-ação/reflexão-na-ação}

É então estudando o que torna os profissionais competentes nas zonas indeterminadas da prática que encontraremos a expressão "talento artístico", que é inerente ao profissional que se busca desenvolver. O talento artístico deve ser estudado "através do estudo cuidadoso das performances mais competentes." (Schön, p. 22, 2000) e além disso, as ciências aplicadas e a técnica fazem fronteiras com o talento artístico e "há uma arte da sistematização de problemas, uma arte da implementação e uma arte do improviso" que são necessárias para conceber na prática o uso da ciência aplicada e da técnica.

No ensino de artes há também uma chave que pode nos auxiliar na busca do profissional reflexivo. O método de ensino atual é construído majoritariamente com bases no 'aprender fazendo', da performance e do improviso experimental, ficando distante das ciências e do conhecimento acadêmico aplicado. "Ao estudante, não se pode ensinar o que ele precisa saber, mas se pode instruir[...]" (Schön, p. 25, 2000) pois somente o profissional pode ver por seus próprios olhos e enxergar à sua própria maneira, mesmo sendo o professor dessa forma o seu guia, ele servirá apenas como ajuda.

Frente a um problema que não se consegue resolver pelas vias normais de resolução, o profissional talentoso age usando um conhecimento que ele não consegue descrever em palavras, que surge, o que na verdade fazemos isso todos os dias em ações corriqueiras, como andar "[...] o conhecimento implícito em suas ações é incoerente com sua descrição" (Schön, p. 22, 2000). Daí surge a expressão "conhecer-na-ação", que diz respeito ao conhecimento que se revela durante a ação, através de uma performance espontânea. Podemos, usando a reflexão e a observação, explicar o funcionamento velado de nossas performances, mas sempre serão construções a posteriori, sugerindo que o conhecimento é algo estático enquanto o conhecer é dinâmico. Executamos essas ações sem precisar pensar a respeito.

Em casos inesperados ou de conflito é que a reflexão-naação surge como uma etapa de criticar o nosso conhecer-naação. Uma surpresa chama nossa atenção e agimos, até certo ponto, de forma consciente dentro de um "presente-na-ação" na busca de encarar esse momento de surpresa no sentido de "reestruturar as estratégias de ação, as compreensões dos fenômenos ou as formas de conceber (novos) problemas" se utilizando da experimentação súbita para preparar-se uma nova reflexão a respeito de outro problema ou a solução final do problema.

Uma situação de improviso reflete bem o sentido de refletir-na-ação. Quando uma banda está fazendo um improviso em grupo e em determinado momento o saxofonista começa a solar, ele estará improvisando ou é possível que o solo já esteja construído previamente em sua cabeça, seja uma composição de outra pessoa, seja uma composição sua construída momentos antes de começar a tocar, ou até mesmo momentos antes de começar a solar, partindo dos princípios de um já determinado caminho teórico musical ('tocar numa escala de harmonia $\mathrm{x}$, num ritmo $\mathrm{y}$, desconstruindo ou não essas bases durante o solo). Se ele estiver realmente improvisando é provável que ele não saiba reproduzir o solo inteiramente igual novamente e que não saiba dizer que caminhos tomou durante o solo. Ao mesmo tempo, os outros integrantes da banda estarão improvisando em cima do solo do saxofonista, sem se falar, a banda seguindo então uma espécie de caminho único de acordo com conhecimentos implícitos, improvisando. "Cada músico faz invenções sequenciais e responde a surpresas desencadeadas pelas invenções dos outros, mas o processo coletivo da invenção musical é organizado em torno de uma estrutura básica. [...] À medida que os músicos sentem as direções nas quais a música está desenvolvendo-se, eles produzem novas compreensões dela." Porém, deve-se lembrar que "sermos capazes de refletirna-ação é diferente de sermos capazes de refletir sobre nossa reflexão-na-ação, de modo a produzir uma boa descrição verbal dela." (Schön, p. 35, 2000)

\section{O ensino da prática}

Aprendemos uma prática sozinhos, através de um profissional ou mestre mais experiente ou entramos numa atividade de ensino prático. cada uma dessas opções tem seus benefícios e seus maleficios: a prática por conta própria experimenta liberdade de visão mas começa-se do zero, sem ganhar experiências exteriores a ele. Aprender com um mestre experiente, como um artesão, tem a vantagem de estar mais perto da realidade da prática e dos padrões de trabalho, mas carrega a desvantagem de os escritórios e fábricas precisarem concluir um processo de iniciação e educação nos empregados, 
o que leva tempo e aumenta o preço do erro, no sentido de sempre solicitar um alto desempenho.

A atividade de ensino prático consiste em uma aula prática, um mundo virtual que foi projetado para aprendermos uma prática, através do aprender-fazendo. Os estudantes trabalham projetos que estimulam e simplificam ou projetos reais sob uma supervisão minuciosa. É um lugar relativamente livre de fatores do mundo real que possam prejudicar ou diminuir a imersão no projeto. São aulas orientadas por um profissional experiente e muitas práticas em grupo que por vezes substituem o coordenador em seu papel de demonstrar, aconselhar, questionar e criticar. (Schön, 2000).

Na perspectiva da racionalidade técnica, a prática secoloca como uma busca objetiva de resultados que já se pretendem encontrar, e toda a sua gama de conhecimento profissional está fundada sobre uma base de fatos, lidando com situações familiares. Dessa forma, o conhecimento profissional se torna um "Treinamento técnico. O trabalho do instrutor será comunicar e demonstrar a aplicação de regas e operações aos fatos da prática." (schon 41). Há também casos em que as características da situação não sugerem de imediato uma resolução através de teorias e conhecimentos de forma clara. Ele as utiliza em uma "investigação autogovernada" (schon 38), ou seja, que segue regras para encontrar informações e dados que tornem clara a resposta de uma situação problemática. Utilizar a reflexão-na-ação pretende não somente descortinar novos métodos de raciocínio mas ir além e experimentar, edificar novos modos de entendimento, "estratégias de ação e formas de conceber problemas". O profissional instrutor reforçará a prática em zonas indeterminadas e reflexões em conjunto sobre as situações, lembrando que nenhum tipo de ensino interdita a ação do outro, pelo contrário, eles devem fazer parte de um mesmo processo.

\section{Conclusões}

Pretende-se então produzir planos-pedagógicos que sejam condizentes com a realidade das demandas do mundo atual e estejam assim inseridos dentro de seus respectivos contextos. Tais planos precisam estar fundados firmemente em novas bases epistemológicas de ensino de projeto e gerar um novo paradigma que provoque a ruptura do até então vigente, para que possamos "a partir das condições intelectuais, sociais e técnicas da época e não dos caprichos [...] de alguns arquitetos maníacos por novidades" (Gropius, p. 67, 1972) promover as mudanças básicas e necessárias, de fato.

Os edifícios construídos com as novas tecnologias servem de exemplo para as demais construções, para os estudantes e arquitetos. Principalmente a faculdade de arquitetura deve promover essa mudança e influenciar na divulgação e aceitação do novo paradigma. Na era digital, construir com métodos antigos ou tentar dar prioridade a processos de revitalização da arquitetura seria fazer do passado um espelho para o homem atual, o que não é possível pois houveram enormes transformações nos domínios sociais, tecnológicos e
estéticos.(Gropius, p.115, 1972)

Sufocando o talento artístico do aluno através de um ensino que não estimula o pensamento e a prática, continuamos na superfície sem embrenhar-se dentro de questões mais importantes, que só serão resolvidas através de uma nova postura de ensino. "um ambiente estimulante é tão importante para libertar as energias criativas do estudante quanto o dinamismo do professor" (Gropius, p.111, 1972).

Ao invés de fetichizar formas ou dar popularidade aos starchitects, que acabam por se manter nos limites da moda, podemos usar uma linguagem visual mais adaptada à escala humana, ou as próprias necessidades humanas, sem excessos. Como exemplo disso trago o caso do Neokitsch sustentável. A atitude kitsch (Moles, 1972) vem sendo desde o começo do século XX um exemplo de como a sociedade encara seus objetos de consumo, destacando-se na arquitetura como imenso prazer pela decoração, fazendo do kitsch uma moda sem estilo, a arte de viver. Atualmente o Kitsch sustentável é um exemplo desse tipo de arquitetura-moda, onde prega-se, com louvor, a sustentabilidade em sua forma mais eficiente possível adaptando o projeto formal ao método de construção dos "edifícios" e causando assim certo desconforto estético pela simples aceitação dessa adaptação como projeto final, resolução final de um problema. O profissional reflexivo adaptado às novas ferramentas digitais pode criar parametricamente um modelo com a inserção no software necessário das variáveis corretas relacionadas aos domínios a serem considerados nos problemas que resolve as questões de várias formas possíveis. "a satisfação das necessidades psíquicas é tão importante quanto a das materiais, e no qual o propósito de uma nova concepção espacial é algo mais do que economia estrutural e perfeição funcional" (Gropius, p. 27, 1972).

\section{Referências}

Argan, G. C. (1992). Arte moderna: do iluminismo aos movimentos contemporâneos. São Paulo: Editora Companhia das Letras

Asimow, M. (1962). Introduction to Design. Englewood Cliffs, N.J., Prentice-Hall

Kowaltowski, D. K. ; Moreira, D. de C. ; Petreche, J. R. D. ; Fabrício, M. M. (2011). O Processo de Projeto em Arquitetura da Teoria à Tecnologia. Editora: Oficina de textos

Moles, A. A. (1972). O Kitsch: A Arte da Felicidade. São Paulo, Perspectvia, Ed. da Universidade de São Paulo, Tradução de Sérgio Miceli

Naylor, G. (1985). The Bauhaus Reassessed: Sources and Design Theory. London: Herbert Press

Oxman, R. (2007). Digital Architecture as a Challenge for Design Pedagogy: Theory, Knowledge, Models and Medium. Design Studies (Vol. 9 Issue 2. pp. 99-120).

Oxman, R. (2006). Educating the Digital Design Thinker What do We Teach When We Teach Design

Pupo, R. T. (2009). Inserção da prototipagem e fabricação digitais no processo de projeto: um novo desafio para o ensino de arquitetura. Campinas, SP 
Sacristan, J. G. (2000). O currículo: uma reflexão sobre a prática. Porto Alegre: Artmed

Schön, D. A. (1983). The reflective practitioner: how professionals think in action. Basic Books, New York

Schön, D. A. (2000). Educando o profissional reflexivo: um novo design para o ensino e a aprendizagem. Porto Alegre, Artes Médicas. Versão brasileira.

Woodbury, R. (2010). Elements of parametric design. Routledge

Wingler, H. (1969). The Bauhaus: Weimar Dessau Berlin Chicago. Massachusetts Institute of Technology
Schön, D. A. and Wigging, G. (1992). Kinds of seeing and their functions in Designing. Design StudiesVol 13 No 2

Tramontano M., Soares J. P. (2012). Arquitetura emergente, design paramétricos e o representar através de modelos de informação. V!RUS, São Carlos

Eastman, C. , Teicholz, P. , Sacks, R. , and Liston, K. (2011). BIM handbook: A guide to building information modeling for owners, managers, designers, engineers and contractors, Wiley, New York

Gropius, W. (1972). Bauhaus: Novarquitetura. São Paulo: Perspectiva 